\title{
GIS use of Land Use/Land Cover layers and historical data for water losses indices
}

\author{
Alexandru Aldea ${ }^{1, *}$, Mihaela Aldea ${ }^{2}$, and Sorin Perju ${ }^{3}$ \\ ${ }^{1}$ Technical University of Civil Engineering, Hydraulics and Environmental Protection Department, 020396 Bucharest, Romania \\ ${ }^{2}$ Technical University of Civil Engineering, Civil Engineering Department, 020396 Bucharest, Romania \\ ${ }^{3}$ Technical University of Civil Engineering, Hydrotechnics Engineering Department, 020396 Bucharest, Romania
}

\begin{abstract}
The population growth and/or its use and development of the land is a continuous preoccupation of the decision factors regarding the water supply system in general and the development of the potable water distribution networks in particular. This issue is even more critical especially in the areas of big cities and important urban growing. As the urbanization of land outgrows the existing water supply systems, one of the possible solutions is to expand the water distribution network in order to cover this urban growth. The present paper analyses further the possibilities to define and use certain indices of urban development together with water loss indices in order to determine trends or issues related with the provision of water supply services and connectivity.
\end{abstract}

\section{Introduction}

Drinking water infrastructure is one of the most important infrastructures that should be considered besides transportation in analyzing the needs and the constraints for the recently developed urban areas and a city's urban growth. The problem for the water supply infrastructure arises from the further growth of the urban areas, away from the crowded town centers and the variations in population density and the water distribution adjustments, which are induced by this trend and their implications on the water loss volume.

Romania, an EU member country has a water supply network of more than $79000 \mathrm{~km}$ of distribution mains and service laterals as recorded in 2016 [1], many of them in service for longer than 40 years [2]. Leakage rates and water loss through pipelines varies significantly, but there are some possibilities of estimation as exemplified in a study [3] over the data in four countries on two continents which shows that the distribution of burst frequencies across the water supply network follow the Pareto principle, about $80 \%$ of the distribution network experiencing less than 2 failures $/ \mathrm{km} /$ year, only $1 \%$ of the network breaking at a frequency of 4 failures $/ \mathrm{km} /$ year or more.

On this account, the length of the pipes was taken into consideration as an important indicator to be used in our analysis presented further in this paper.

\section{Data and methods used in GIS
analysis for water losses in Bucharest \\ 2 Data and methods used in GIS
analysis for water losses in Bucharest case study}

Bucharest is the largest city of Romania and its capital. Next, we present the case study on the urban growth and population dynamics of the Bucharest metropolitan area and the indicators which may be affected or affect the drinking water infrastructure.

The study at such a complex level as a metropolitan area implied the use of a variety of data sources, not only from multiple domains and in different forms and formats but also from several periods of time. There were three main categories of datasets which were identified, obtained or produced and then used in our analysis.

The first set used for the analysis is the GIS dataset containing the Land Use/Land Cover Classes which can be obtained from the classification of different time series of satellite imagery. For this dataset, we propose the use of the following four major types of consumers which influence the water consumption indicator:

- Economic consumers (both industrial and commercial) which means that they are big consumers

- High density residential consumers (tall residential or office buildings) which means a big number of connections/area

- Medium density consumers (individual houses) which means a smaller number of connections/area with reduced consume of potable water

- Low density consumer (recently urbanized individual houses with bigger parcels) which means a potential of an increased consume for the summer garden watering with potable water

The four types of consumers presented above can be then identified in the various satellite images available from different governmental agencies such as USGS or ESA, since they are recently accessible at low or no cost,

\footnotetext{
* Corresponding author: aldea\#hidraulica.utcb.ro.org
} 
for different periods. The identification of the mentioned consumer categories is possible as for the large scale such as the city scale or the metropolitan area scale the four types of consumer areas exhibit certain shapes and distinctive spatial arrangements recognizable in the Land Use and Land Cover patterns.

The second dataset that we found suitable for our analysis is the one containing the historical values for the water loss indices available for the current water supply

and distribution system: real losses/network length/day; real losses/connection/day and water losses/capita/day. These data are specific data usually collected and recorded by the water companies.
The last set of data usable in these type of analyses is the one containing additional but suggestive information such as the historical recordings of the statistical data regarding the population and demographics (e.g. the Census data); the distribution of population/square $\mathrm{km}$; utility companies' reports and archives; urban area maps, water network maps etc.

In the context presented above, our study covers the case of Bucharest making use of all the data available for such a complex analysis, and attempts to find the key factors and indicators that, in general, impact the drinking water networks on the operational level and regarding the water loss implications on infrastructure.

Tabel 1. Land Use/Land Cover (LULC) classes defined based on the consumer categories.

\begin{tabular}{|l|l|l|l|l|}
\hline Classes & HiRes & MedRes & LowRes & MedComInd \\
\hline Full name & High residential & Medium residential & Low residential & $\begin{array}{l}\text { Medium commercial or } \\
\text { industrial }\end{array}$ \\
\hline Classes & $\begin{array}{l}\text { High-rise residential } \\
\text { units but less dense built- } \\
\text { up with or without green } \\
\text { space between them, } \\
\text { medium needs of water } \\
\text { due to the many stories. }\end{array}$ & $\begin{array}{l}\text { Low-rise residential } \\
\text { units but very dense } \\
\text { buitt-up with or } \\
\text { courtyards, reduced } \\
\text { needs of water. }\end{array}$ & $\begin{array}{l}\text { Low-rise rural residential } \\
\text { units but less dense built- } \\
\text { up with large gardens, } \\
\text { needs of water especially } \\
\text { for gardens. }\end{array}$ & $\begin{array}{l}\text { Low-rise to medium-rise } \\
\text { commercial or industrial } \\
\text { units but with large } \\
\text { impervious surfaces, } \\
\text { greenhouses, very high } \\
\text { needs of water. }\end{array}$ \\
\hline
\end{tabular}

For Bucharest and the urbanized area surrounding it, the four major types of consumers are specified above, in Table 1, and were determined based on the specificity of the Land Use and Land Cover classes identified for this particular city.

Next, the evolution of the area of the four types of Land Use and Land Cover for the Bucharest metropolitan area

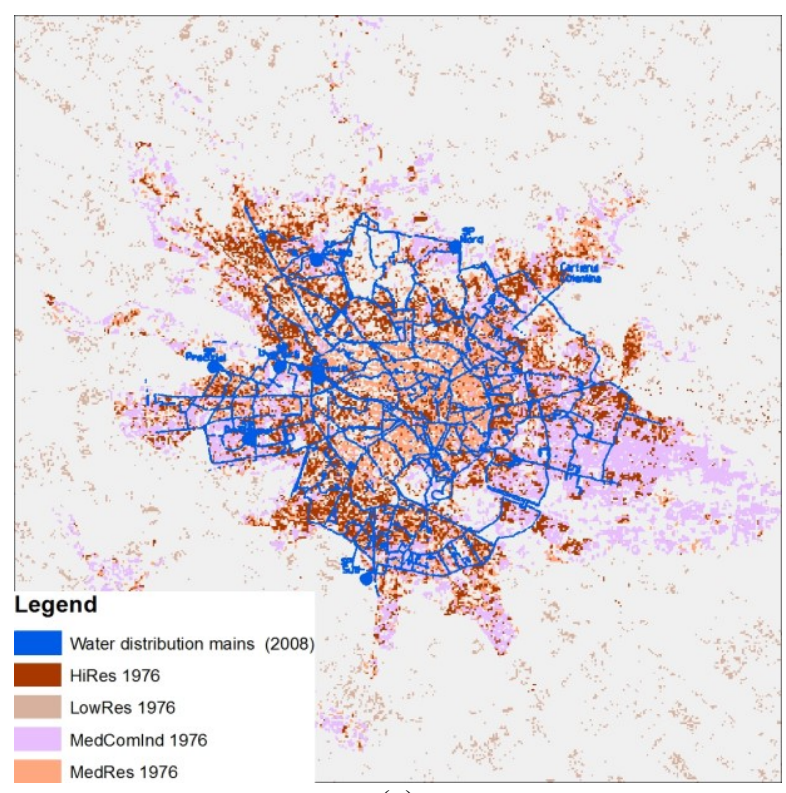

(a) was calculated with the help of the vector polygons obtained from the classification of the Landsat satellite images over four decades in time. The areas of these surfaces could then be calculated and correlated with the statistical values recorded as close as possible to the same periods of time and also correlated with the water mains coverage extracted from the additional datasets [1], [4],[5].

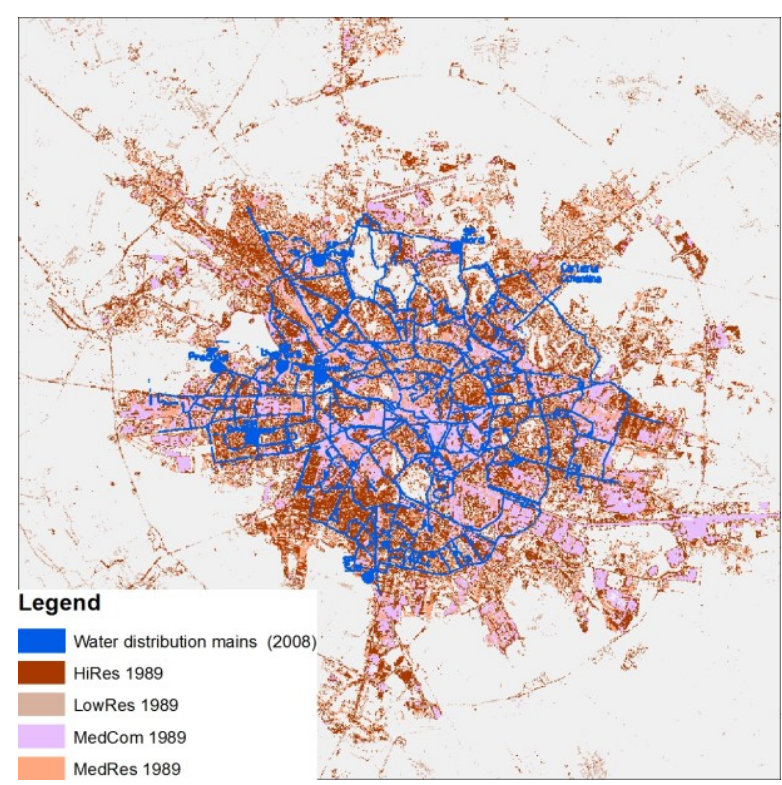

(b) 


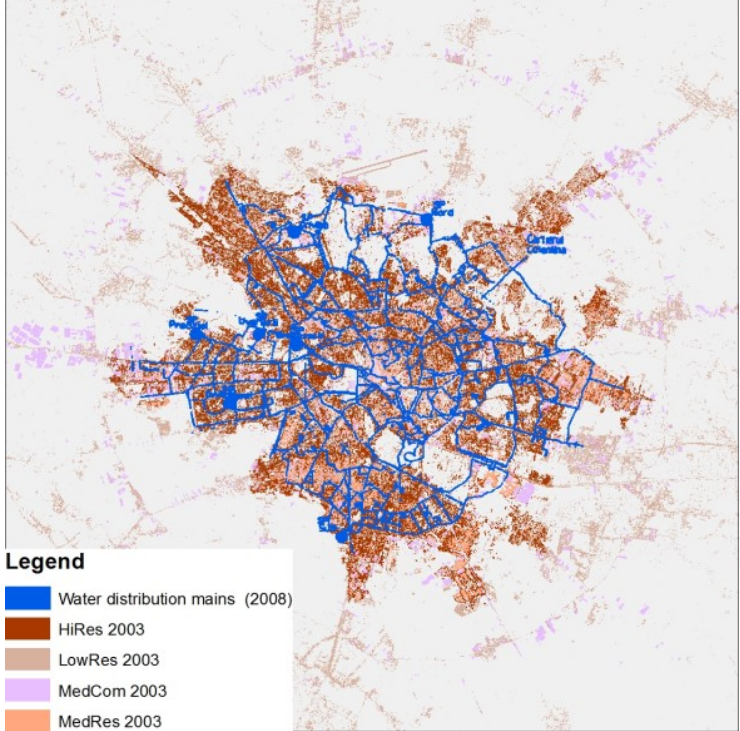

(c)

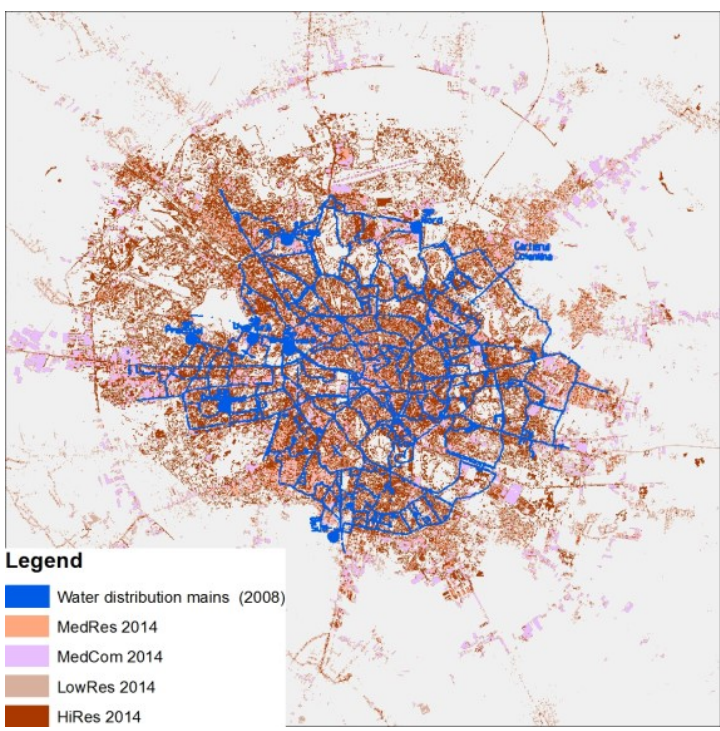

(d)

Fig. 1. The GIS layers for the Bucharest city case, obtained based on the satellite image processing (namely classification of the imagery into Land Use/Land Cover classes): (a) GIS layers for the corresponding LULC classes for the year of 1976; (b) GIS layers for the corresponding LULC classes for the year of 1989; (c) GIS layers for the corresponding LULC classes for the year of 2003; (d) GIS layers for the corresponding LULC classes for the year of 2014

The water company in Bucharest, Apa Nova Bucharest, a private operator part of the Veolia group, provided all

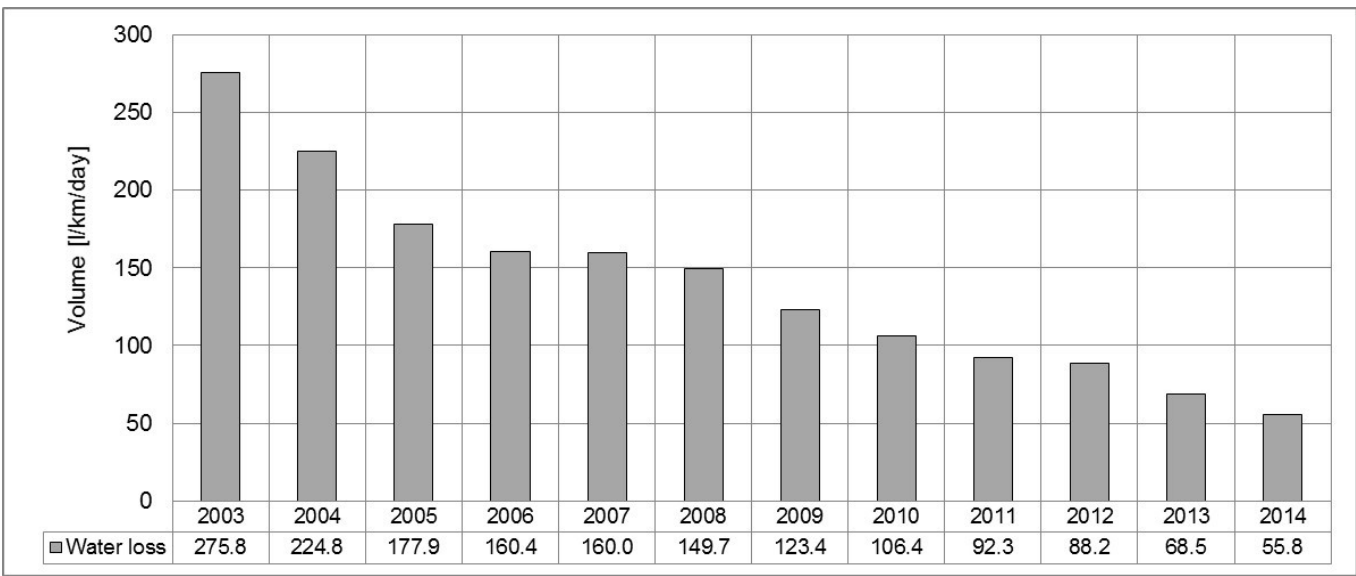

Fig. 2. Water Losses in $1 / \mathrm{km} /$ day.

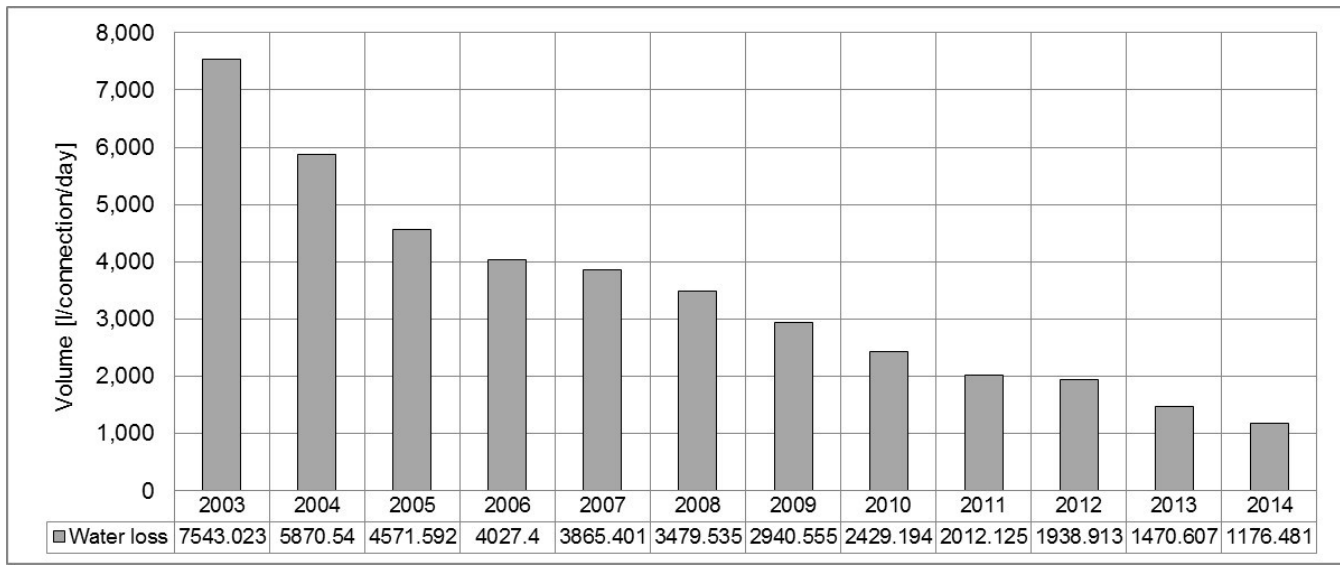

Fig. 3. Water Losses in 1/connection/day. 


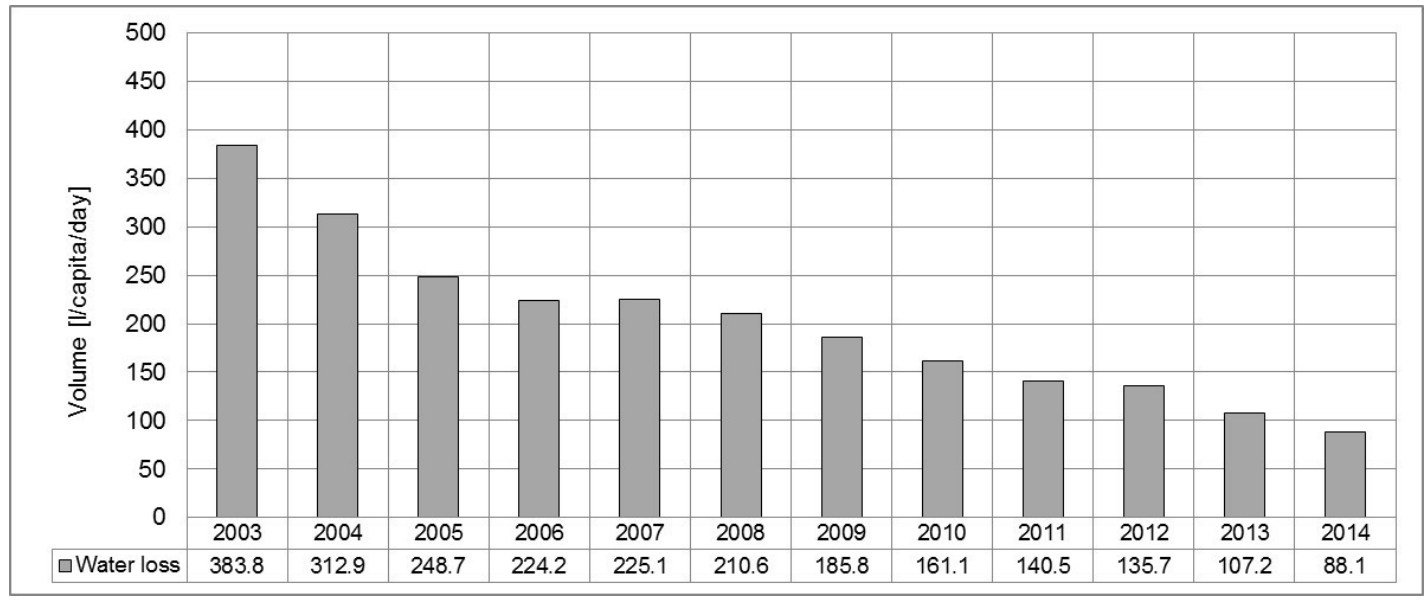

Fig. 4. Water Losses in 1/capita/day

The third dataset assembled for Bucharest case was constructed by consulting historical archives of the various statistical recordings or reports [6], [7], the main indicators which were isolated from this massive amount of data being those which could be correlated with the actual water loss indicators, such as pipe lengths, population, urbanized area, connection etc. They are presented in Table 2:

Table 2. The third set of data from Bucharest additional sources.

\begin{tabular}{l|l|l|l|l|l|l}
\hline Year & $\mathbf{1 9 2 5}$ & $\mathbf{1 9 4 3}$ & $\mathbf{1 9 7 5}$ & $\mathbf{1 9 9 2 - 9 5}$ & $\mathbf{2 0 0 0 - 0 3}$ & $\mathbf{2 0 1 3 - 1 5}$ \\
\hline Official city area [ha] & $-5,075$ & 9,873 & - & 15,250 & 15,250 & 23,787 \\
Official metropolitan area & - & - & - & 423 & 4,123 & 19,215 \\
$\begin{array}{l}\text { Daily medium water flow [m3/day]- } \\
\text { metropolitan area }\end{array}$ & - & - & - & - & 10,315 & 21,117 \\
$\begin{array}{l}\text { Daily medium water flow [m3/day]-city } \\
\text { Population in the city [mil] }\end{array}$ & 80,073 & 137,085 & 905,320 & 981,643 & 867,408 & $1,056,698$ \\
Population in metropolitan area & 0.9 & 1.041 & 1.807 & 2.067 & 2.151 & 2.161 \\
Distribution pipes length [km]-metropolitan \\
area
\end{tabular}

\section{Results and discussions}

The option of extending the present system over the areas of urban growth is analyzed and the net value of expansion taken into consideration is the Land Use and Land Cover area calculated in ArcGIS for the entire built-up area, but without taking into account the open space inside the city. As it can be shown in Table 3, the city boundary is much larger than the actual built-up space inside, including many parks and open space. As we were interested rather in the connection number which takes place on the built-up space, this seems to be a better suited indicator. Thus, the extension of the water distribution system can vary between $165 \mathrm{~km}$ and 215 $\mathrm{km}$ of new mains, while the losses can vary between $59,600 \mathrm{l} /$ day and $9200 \mathrm{l} /$ day, taking into consideration the historical values.
Table 3. Change detection based on two decades of data regarding water losses.

\begin{tabular}{|r|c|c|c|}
\hline & $\mathbf{2 0 0 3}$ & $\mathbf{2 0 1 4}$ & $\begin{array}{c}\text { Change } \\
\text { detection }\end{array}$ \\
\hline Water Loss [1/km/day] & 275.8 & 55.8 & -220 \\
\hline Water mains length [km] & 2,185 & 2600 & 415 \\
\hline Water Loss [1/day] & 602623 & 145080 & -457543 \\
\hline $\begin{array}{r}\text { City boundary [km2] } \\
\text { length/square km of city }\end{array}$ & 152.50 & 237.87 & 85.37 \\
\hline $\begin{array}{r}\text { LULC Classes without } \\
\text { LowRes [km2] }\end{array}$ & 120.38 & 157.41 & 37.03 \\
\hline $\begin{array}{r}\text { LULC Classes only } \\
\text { LowRes [km2] }\end{array}$ & 99.93 & 77.99 & -21.94 \\
\hline
\end{tabular}




\begin{tabular}{|r|c|c|c|}
\hline $\begin{array}{r}\text { LULC Classes with } \\
\text { LowRes [km2] }\end{array}$ & 220.31 & 235.40 & 15.09 \\
\hline
\end{tabular}

To conclude, it is important to emphasize that statistical data cannot be satisfactory used without GIS and spatial information, this is why the GIS layers obtained from the Land Use and Land cover classes, together with the statistical and water loss data can add valuable information in the process of decision making.

\section{References}

1. Romanian National Institute of Statistics. INSSE Statistical DB - TEMPO-Online time series, www.insse.ro. Available online: http://statistici.insse.ro/shop/index.jsp?page=tempo3 \&lang=ro\&ind $=$ GOS106C2017, $\quad$ (accessed on 14 September 2017).

2. Romanian Ministry of Regional Development and Public Administration. Guidelines regarding the rehabilitation of pipelines used for the transportation of water (raw, clean, used, treated wastewater etc.). Bucharest, 2014.

3. Pearson, D., Fantozzi, M., Soares, D., Waldron, T. Searching for N2: How does Pressure Reduction Reduce Burst Frequency? Proc. IWA Leakage Conf., 2005, p. 13.

4. Perju, S., Georgescu, A., Anton, A., \& Sandu, L. Operation optimization of several repumping stations interconnected to a complex water distribution network-case study. World Water Congress and Exhibition, Vienna, 2008, p. 8.

5. Aldea, A., \& Aldea, M. The interrelationships between urban dynamics and water resource and supply based on multitemporal analysis. Proc. SPIE, Fourth International Conference on Remote Sensing and Geoinformation of the Environment (RSCy2016), 96881B, Paphos, 2016

6. Bucharest Water Plant. Annual Report. Royal Court Typography F.Gobl and Sons Bucharest, 1925.

7. Giurescu, C. History of Bucharest from the oldest times until today. Lierature Press, Bucharest, 1966 